\title{
Taxa de passagem e parâmetros ruminais em bovinos suplementados com enzimas fibrolíticas ${ }^{1}$
}

\author{
Adriana de Souza Martins ${ }^{2}$, Paulo de Figueiredo Vieira ${ }^{3}$, Telma Teresinha Berchielli ${ }^{4}$, Ivanor \\ Nunes do Prado ${ }^{5}$, Roberta Carrilho Canesin ${ }^{6}$, Mara Cristina Setti ${ }^{7}$ \\ ${ }^{1}$ Parte da tese de Doutorado em Zootecnia apresentada pela primeira autora à FCAV/UNESP, financiada pelo CNPq e, parcialmente, pela \\ FUNDUNESP. \\ ${ }^{2}$ Cursos de Agronomia e Zootecnia do CESCAGE. Av. Carlos Cavalcanti, s/n CEP: 84030-000, Ponta Grossa - PR. \\ ${ }^{3}$ Curso de Zootecnia da Universidade José do Rosário Vellano - UNIFENAS, Rodovia MG 179, km 0, CEP: 37130-000. \\ ${ }^{4}$ Depto. de Zootecnia da FCAV/UNESP, Pesquisador do CNPq. Rod. Carlos Tonnani km 5, CEP: 14870-000, Jaboticabal - SP. \\ ${ }^{5}$ Depto. de Zootecnia da UEM, Pesquisador do CNPq. Av. Colombo, 5790, CEP: 87020-900. \\ ${ }^{6}$ Mestrando em Zootecnia pela FCAVIUNESP. Rod. Carlos Tonnani km5, CEP: 14870-000, Jaboticabal - SP. \\ ${ }^{7}$ Depto. de Zootecnia da UNOESTE, Rod. Limoeiro Tavares, km 572 CEP: 19067-175, Presidente Prudente - SP.
}

RESUMO - Avaliou-se o efeito da adição de enzimas fibrolíticas (celulase e xilanase) sobre as taxas de passagem de partículas e de diluição e os parâmetros ruminais ( $\mathrm{pH}$ e nitrogênio amoniacal) em animais consumindo dietas contendo silagem de milho e feno de tifton 85 (Cynodon spp.) como volumoso. Oito bovinos com fístulas no rúmen e no duodeno foram distribuídos em dois quadrados latinos 4 × 4, com os tratamentos distribuídos em esquema fatorial 2 × 2 (duas fontes de volumoso e adição ou não de enzimas). O complexo enzimático foi proveniente de fonte comercial e extraído dos fungos Aspergillus niger e Trichoderma longibrachiatum, sendo fornecido na proporção de $12 \mathrm{~g} / \mathrm{animal} / \mathrm{dia}$, misturado à ração total. Para as taxas de passagem, foram utilizados como marcadores das fases sólida e líquida o cromo-mordente e o cobalto-EDTA, respectivamente. Não houve efeito das enzimas sobre o $\mathrm{pH}$ e as concentrações de $\mathrm{N}-\mathrm{NH}_{3}$, que apresentaram médias de 6,5 e $22,10 \mathrm{mg} / 100 \mathrm{~mL}$, respectivamente. A taxa de passagem de partículas no rúmen não foi influenciada pela suplementação enzimática, com médias de 3,4 e $3,0 \% / \mathrm{h}$ para as dietas contendo silagem de milho e feno de tifton, respectivamente. A taxa de diluição aumentou de 10,07 para $11,84 \% / \mathrm{h}$ com a adição de enzimas. A suplementação com enzimas fibrolíticas em dietas formuladas com silagem de milho e feno de tifton como volumoso praticamente não alterou os parâmetros avaliados.

Palavras-chave: celulase, feno de tifton, ruminantes, silagem de milho

\section{Passage rate and ruminal parameters in cattle supplemented with fibrolytic enzymes}

\begin{abstract}
The objective of this trial was to evaluate the effect of fibrolytic enzymes (cellulase and xylanase) on particle passage rate, dilution rate and ruminal parameters $(\mathrm{pH}$ and ammonia $\mathrm{N}$ ) in animals fed diets containing corn silage or Tifton 85 hay (Cynodon spp.). Eight bovines fitted with ruminal and duodenal cannulas were randomly assigned to two $4 \mathrm{x} 4$ Latin squares in a $2 \times 2$ factorial arrangement of treatments (two forage sources supplemented or not with fibrolytic enzymes). A commercial enzymatic complex containing enzymes extracted from Aspergillus niger and Trichoderma longibrachiatum fungi was mixed in the ration and fed $(12 \mathrm{~g})$ daily to each animal. Chromium-mordant and Co-EDTA were used as solid and liquid phase markers, respectively, to estimate passage rates. There was no effect of enzymatic supplementation on ruminal $\mathrm{pH}$ and ammonia $\mathrm{N}$ averaging 6.5 and $22.10 \mathrm{mg} / 100 \mathrm{~mL}$, respectively, across diets. Similarly, ruminal particle passage rate was not affected by the enzymatic supplementation with mean values of 3.4 and $3.0 \% / \mathrm{h}$ for animals fed corn silage and Tifton hay, respectively. However, ruminal dilution rate increased from 10.07 to $11.84 \% / \mathrm{h}$ with enzymatic supplementation. Feeding fibrolytic enzymes to bovines had little effect on the measured variables.
\end{abstract}

Key Words: cellulase, corn silage, ruminants, tifton hay

\section{Introdução}

Os ruminantes são encontrados em uma variedade de nichos ecológicos por serem capazes de utilizar os carboidratos fibrosos presentes na parede celular dos vegetais, por meio da simbiose entre uma população microbiana diversificada presente no rúmen. Esses animais possuem a capacidade de aproveitar de forma eficiente alimentos de baixa qualidade (volumosos).

Apesar da habilidade dos microrganismos ruminais na digestão da celulose e de outros carboidratos fibrosos, fatores relacionados à estrutura e composição da planta, 
como as interações físico-químicas entre os constituintes da parede celular, particularmente as ligações entre a matriz de hemicelulose e lignina e os aspectos relacionados ao animal, como a mastigação, salivação e pH ruminal, podem limitar a extensão da digestão no rúmen, por representarem uma barreira física aos processos fibrolíticos.

$\mathrm{Na}$ utilização dos produtos biotecnológicos, têm-se destacado estudos avaliando o efeito da suplementação com enzimas fibrolíticas exógenas (celulase e hemicelulase), que teriam a capacidade de potencializar a degradação dos polissacarídeos fibrosos juntamente com as enzimas produzidas pelos microrganismos do rúmen, estimulando a digestão total e a taxa de degradação (Newbold, 1997).

Resultados obtidos com a adição de enzimas fibrolíticas em dietas para ruminantes têm comprovado aumento na degradabilidade da MS e FDN (Feng et al., 1996), na produção de leite (Schingoethe et al., 1999) e no ganho de peso em bovinos (Beauchemin et al., 1995).

Em alguns estudos, observou-se que as enzimas fibrolíticas poderiam alterar a utilização dos alimentos pelos ruminantes por meio de efeito direto sobre a fibra (Feng et al., 1996) ou pelo aumento da digestão ruminal e/ou pós-ruminal (Hristov et al., 2000), ocorrendo sinergismo com os microrganismos do rúmen. De fato, estas formas de ação estariam interligadas, de modo que as alterações mediadas pelas enzimas antes do consumo refletiriam nas digestões ruminal e pós-ruminal dos nutrientes (McAllister et al., 2001).

Lewis et al. (1996) avaliaram diferentes métodos de aplicação das enzimas fibrolíticas em novilhos e não observaram efeito do fornecimento das enzimas via cânula ruminal, em comparação ao fornecimento direto na forragem, sobre as características digestivas. Segundo esses autores, as enzimas poderiam ter sido digeridas ou estar suspensas na fase fluida do conteúdo ruminal, sendo eliminadas do rúmen antes de um contato suficiente com as partículas de alimento para hidrólise.

A taxa de passagem de fluidos no rúmen pode variar conforme o nível de ingestão, a proporção de concentrado, o indicador utilizado e os locais de amostragem no rúmen (Owens \& Goetsch, 1988). Beauchemin et al. (1999), em experimento com vacas em lactação, não constataram efeito da adição de enzimas fibrolíticas sobre a taxa de diluição, mas notaram redução no tempo de retenção ruminal das partículas.

A eficiência das enzimas fibrolíticas na produção animal tem sido observada em vários experimentos, entretanto, não há informações suficientes para garantir a consistência e a magnitude destas respostas.

Chesson (1993) considerou que a liberação no meio ruminal poderia expor as enzimas exógenas às condições desfavoráveis (temperatura, $\mathrm{pH}$ e condições físicas da digesta), comprometendo sua estrutura e, conseqüentemente, limitando sua atividade no substrato.

Desta forma, é necessária a avaliação, em bovinos, de metodologias que considerem o modo de ação, a composição, a especificidade e a eficiência dos complexos enzimáticos provenientes de fungos ou bactérias, que, posteriormente, possam ser utilizados comercialmente ou mesmo para seleção genética e transferência para outras espécies (Varga \& Kolver, 1997).

Este trabalho foi realizado com o objetivo de determinar o efeito de enzimas fibrolíticas exógenas (celulase e xilanase) sobre as taxas de diluição e passagem de partículas, o pH e o nitrogênio amoniacal no fluido ruminal de bovinos alimentados com dietas compostas de silagem de milho e feno de tifton 85 .

\section{Material e Métodos}

O experimento foi desenvolvido no Setor de Avaliação de Alimentos do Departamento de Zootecnia da Faculdade de Ciências Agrárias e Veterinárias, Campus de Jaboticabal/ UNESP-SP, no período de novembro de 2001 a fevereiro de 2002.

Foram avaliadas quatro dietas - duas formuladas com silagem de milho, com (SMCE) e sem (SMSE) adição de enzimas fibrolíticas, e duas com feno de tifton 85 , com (FECE) e sem (FESE) adição de enzimas fibrolíticas - elaboradas com base na ingestão de energia metabolizável fermentável e de proteína degradável no rúmen (Tabela 1), segundo recomendações do AFRC (1995).

As enzimas fibrolíticas utilizadas foram provenientes de fonte comercial $^{1}$ (Fibrozyme - ALLTECH - Empresa Bioltecnológica de Produção Animal ) e extraídas dos fungos Aspergillus niger e Trichoderma longibrachiatum. O produto foi constituído de celulase e xilanase e de um surfactante (extrato de Yucca echtigera), veículo com a função de aumentar o contato das enzimas com o substrato.

A atividade enzimática foi de aproximadamente 100 unidades de xilanase (UX) por grama do produto comercial, o que corresponde à quantidade de enzima requerida para liberar um micromol de xilose, obtida em temperatura de $39^{\circ} \mathrm{C} \mathrm{e} \mathrm{pH} 4$. O produto foi fornecido na proporção de $12 \mathrm{~g} /$ animal/dia, sendo misturado ao sal mineral e à ração total.

Diariamente, foram fornecidos $40 \mathrm{~g}$ de suplemento mineral e vitamínico mais a dieta completa (volumoso + concentrado), fornecida duas vezes ao dia.

Foram utilizados oito bovinos com peso vivo médio de $340 \mathrm{~kg}$, providos de cânula no rúmen e no duodeno. O 
Tabela 1 - Composições percentual e química das dietas (\%MS) Table 1 - Ingredient and chemical composition of diets (\% DM)

\begin{tabular}{|c|c|c|c|c|}
\hline \multirow[b]{2}{*}{$\begin{array}{l}\text { Ingrediente } \\
\text { Ingredient }\end{array}$} & \multicolumn{4}{|c|}{$\begin{array}{c}\text { Dieta (\%MS) } \\
\text { Diet }(\% D M)\end{array}$} \\
\hline & $\begin{array}{l}\mathrm{SMSE}^{1} \\
\mathrm{CS}^{1}\end{array}$ & $\begin{array}{l}\mathrm{SMCE}^{2} \\
C S F E^{2}\end{array}$ & $\begin{array}{c}\mathrm{FESE}^{3} \\
T H^{3}\end{array}$ & $\begin{array}{l}\mathrm{FECE}^{4} \\
T H F E^{4}\end{array}$ \\
\hline $\begin{array}{l}\text { Silagem de milho } \\
\text { Corn silage }\end{array}$ & 69,93 & 69,92 & - & - \\
\hline $\begin{array}{l}\text { Feno de tifton } 85 \\
\text { Tifton } 85 \text { hay }\end{array}$ & - & - & 68,47 & 68,50 \\
\hline $\begin{array}{l}\text { Milho } \\
\text { Corn }\end{array}$ & 20,74 & 20,73 & 20,80 & 20,78 \\
\hline $\begin{array}{l}\text { Levedura } \\
\text { Yeast }\end{array}$ & 8,85 & 8,86 & 10,25 & 10,22 \\
\hline $\begin{array}{l}\text { Enzimas fibrolíticas } \\
\text { Fibrolytic enzymes }\end{array}$ & - & 0,13 & - & 0,13 \\
\hline $\begin{array}{l}\text { Sal mineral } \\
\text { Trace minerals }\end{array}$ & 0,50 & 0,51 & 0,50 & 0,51 \\
\hline $\begin{array}{l}\text { Nutriente } \\
\text { Item }\end{array}$ & & & & \\
\hline $\begin{array}{l}\text { MS } \\
D M\end{array}$ & 48,48 & 48,57 & 89,22 & 89,25 \\
\hline $\begin{array}{l}\mathrm{MO} \\
O M\end{array}$ & 87,46 & 87,42 & 83,77 & 83,74 \\
\hline $\begin{array}{l}\mathrm{PB} \\
C P\end{array}$ & 10,93 & 10,95 & 10,83 & 10,82 \\
\hline $\begin{array}{l}\mathrm{FDN} \\
N D F\end{array}$ & 40,32 & 40,21 & 57,85 & 57,83 \\
\hline $\begin{array}{l}\mathrm{FDA} \\
A D F\end{array}$ & 19,17 & 19,12 & 29,96 & 29,94 \\
\hline $\begin{array}{l}\text { Celulose } \\
\text { Cellulose }\end{array}$ & 15,58 & 15,53 & 24,04 & 24,03 \\
\hline $\begin{array}{l}\text { Hemicelulose } \\
\text { Hemicellulose }\end{array}$ & 21,15 & 21,09 & 27,89 & 27,88 \\
\hline
\end{tabular}

${ }^{1}$ Silagem de milho sem adição de enzimas fibrolíticas; ${ }^{2}$ Silagem de milho com adição de enzimas fibrolíticas; ${ }^{3}$ Feno de tifton sem adição de enzimas fibrolíticas; ${ }^{4}$ Feno de tifton com adição de enzimas fibrolíticas.

${ }^{1}$ Corn silage with no fibrolytic enzymes; ${ }^{2}$ Corn silage with fibrolytic enzymes; ${ }^{3}$ Tifton hay with no fibrolytic enzymes; ${ }^{4}$ Tifton hay with fibrolytic enzymes.

experimento foi dividido em quatro períodos de 20 dias, 14 para adaptação dos animais às dietas e seis para coleta do conteúdo ruminal e da digesta duodenal.

Para determinação do $\mathrm{pH}$ e da concentração de nitrogênio amoniacal $\left(\mathrm{N}-\mathrm{NH}_{3}\right)$, amostras de líquido ruminal foram coletadas por meio da cânula ruminal nos tempos zero (antes da alimentação) e 2, 4, 6 e 9 horas após a alimentação. $\mathrm{O} \mathrm{pH}$ foi determinado logo após a coleta, utilizando-se um potenciômetro digital. Para determinar a concentração de $\mathrm{N}-\mathrm{NH}_{3}$, foram coletados $70 \mathrm{~mL}$ de líquido ruminal, o qual foi filtrado, homogeneizado e imediatamente analisado em laboratório. A dosagem de $\mathrm{N}-\mathrm{NH}_{3}$ foi realizada pela técnica Fenner(1965), modificada por Vieira (1980).

A taxa de passagem de fluidos foi estimada utilizando-se o Co-EDTA, segundo Udén et al. (1980), fornecido em dose única de $50 \mathrm{~g}$ por animal, diluído em $500 \mathrm{~mL}$ de água destilada e infundido, através da cânula ruminal, em vários pontos no rúmen. Após a infusão, amostras do fluido ruminal foram coletadas em intervalos de duas horas, durante 12 horas. A concentração de cobalto nas amostras foi determinada por meio da digestão nitro-perclórica e posterior leitura em espectrofotômetro de absorção atômica. A taxa de passagem de fluidos e as curvas de concentração ruminal do cobalto foram ajustadas ao modelo exponencial unicompartimental de Hungate (1966), citado por Colucci (1984):

$$
\mathrm{Y}_{\mathrm{Co}}=\mathrm{A} \cdot \mathrm{e}^{(-\mathrm{k} \cdot \mathrm{\cdot} \cdot \mathrm{t})}
$$

em que $\mathrm{Y}_{\mathrm{Co}}=$ concentração do indicador no tempo t; $\mathrm{A}=$ concentração de equilíbrio do cobalto $(\mathrm{Co}) ; \mathrm{k}_{1}=$ taxa de passagem ou de diluição do Co; e t = tempo de amostragem.

Os parâmetros da dinâmica da fase líquida foram calculados de acordo com Colucci et al. (1990): TR = 1/ $\mathrm{k}_{1 \mathrm{Co}}$

$$
\begin{aligned}
& \mathrm{VLR}=\mathrm{Co} / \mathrm{A} \\
& \mathrm{TF}=\mathrm{k}_{1 \mathrm{Co}} . \mathrm{VLR}
\end{aligned}
$$

em que: TR $(h)=$ tempo de retenção no rúmen; $\mathrm{k}_{1 \mathrm{Co}}(\% / \mathrm{h})=$ taxa de passagem de fluidos; VLR $(\mathrm{L})=$ volume de líquido ruminal; Co $(\mathrm{mg})$ = quantidade de cobalto fornecida; $\mathrm{TF}(\mathrm{L} / \mathrm{h})=$ taxa de fluxo ruminal.

A taxa de reciclagem (TRec) da fase líquida ruminal foi calculada conforme Maeng \& Baldwin (1976): TRec ( $\mathrm{n}^{\circ} \mathrm{de}$ vezes $/$ dia) $=24 \mathrm{~h} / \mathrm{TR}$.

A taxa de passagem da fase sólida das dietas contendo silagem de milho e feno de tifton 85 foi estimada utilizando-se o $\mathrm{Cr}$-mordente, fixado à parede celular do volumoso. Os volumosos foram mordentados com dicromato de sódio, de acordo com o método descrito por Úden et al. (1980). Em cada período experimental, os animais receberam $100 \mathrm{~g}$ de cada volumoso mordentado, através da cânula ruminal, antes da primeira alimentação do dia. Foram coletados aproximadamente $200 \mathrm{~g}$ de fezes, nos seguintes horários: 0 , $6,12,18,24,30,36,42,48,60,84,108$ e 144 horas após o fornecimento do volumoso. Para determinação da taxa de passagem das partículas, utilizou-se o modelo bicompartimental de Grovum \& Williams (1973).

O delineamento utilizado constituiu-se de dois quadrados latinos $4 \times 4$, em esquema fatorial $2 \times 2$. Os dados foram analisados considerando-se os efeitos principais fonte de volumoso (feno de tifton e silagem de milho) e níveis de adição do complexo enzimático ( 0 e $12 \mathrm{~g} /$ animal/dia), bem como suas interações. Os dados de $\mathrm{pH}$ e $\mathrm{N}-\mathrm{NH}_{3}$ foram analisados utilizando-se o modelo de parcelas subdivididas, em que a fonte de alimento e a adição ou não de enzimas foram as parcelas e os tempos de amostragem, as subparcelas. A análise de variância e a comparação de médias pelo teste Tukey, a 5\% de significância, foram obtidas pelo PROC GLM do SAS (1985). 


\section{Resultados e Discussão}

As estimativas das concentrações de nitrogênio amoniacal $\left(\mathrm{N}-\mathrm{NH}_{3}\right)$, de acordo com os tempos de fluido ruminal, são ilustradas na Figura 1.

A adição de enzimas fibrolíticas às dietas contendo silagem de milho e feno de tifton não promoveu diferenças ( $\mathrm{P}>0,05)$ nas concentrações de $\mathrm{N}-\mathrm{NH}_{3}$ ruminal, as quais variaram de 8,01 a $14,72 \mathrm{mg} / 100 \mathrm{mLe}$ de 6,79 a $15,96 \mathrm{mg} / 100 \mathrm{~mL}$, sem e com a adição de enzimas, respectivamente. Para as dietas compostas de feno de tifton sem e com a adição de enzimas fibrolíticas, as variações foram de 9,68 a 16,89 mg/ $100 \mathrm{~mL}$ e de 9,30 a $15,86 \mathrm{mg} / 100 \mathrm{~mL}$, respectivamente.

Para ambos os volumosos, a concentração máxima de $\mathrm{N}-\mathrm{NH}_{3}$ foi obtida duas horas após a alimentação, como observado por Valadares (1997), em novilhos alimentados com dietas contendo diferentes níveis de PB.

A concentração média de amônia foi de $10,25 \mathrm{mg} / 100 \mathrm{~mL}$ para a silagem de milho e de $11,86 \mathrm{mg} / 100 \mathrm{~mL}$ para o feno de tifton. Segundo Satter \& Slyter (1974), a concentração mínima de $\mathrm{N}-\mathrm{NH}_{3}$ necessária para não limitar a síntese microbiana seria de $5 \mathrm{mg} / 100 \mathrm{~mL}$ de líquido ruminal. Entretanto, Van Soest (1994) citou como nível ótimo $10 \mathrm{mg} / 100 \mathrm{~mL}$ de líquido ruminal, valor que não deve ser considerado fixo, pois varia conforme a capacidade de síntese de proteína microbiana, a disponibilidade de substrato e a taxa de fermentação dos carboidratos. As concentrações médias de amônia ruminal obtidas com as dietas experimentais neste estudo foram próximas ao valor citado por Van Soest (1994) e, provavelmente, não limitaram a eficiência de síntese microbiana.

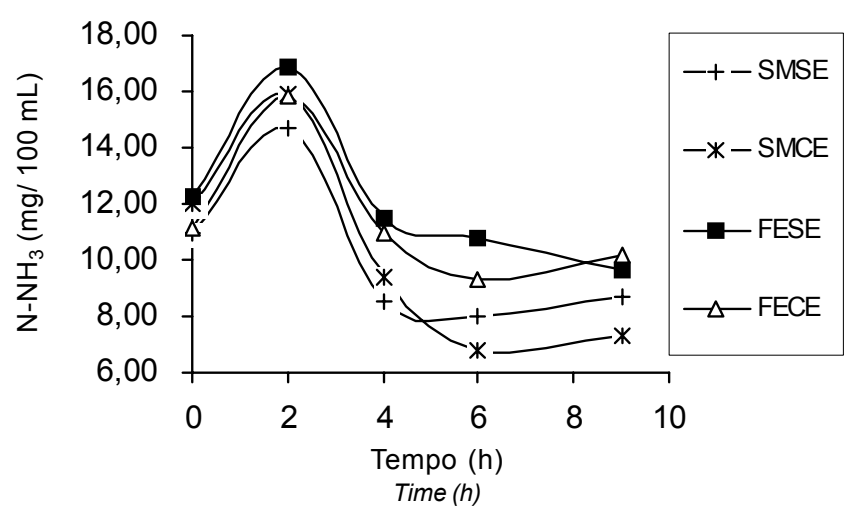

Figura 1 - Concentração de $\mathrm{N}-\mathrm{NH}_{3}$ do fluido ruminal, de acordo com os tempos de amostragem, para as dietas SMSE (silagem de milho sem enzimas fibrolíticas), SMCE (silagem de milho com enzimas fibrolíticas), FESE (feno de tifton sem enzimas fibrolíticas) e FECE (feno de tifton com enzimas fibrolíticas).

Figure 1 - Ammonia Nconcentration in the ruminal fluid of bovines fed CS (corn silage with no fibrolytic enzymes), CSFE (corn silage with fibrolytic enzymes), TH (Tifton hay with no fibrolytic enzymes) or THFE (Tifton hay with fibrolytic enzymes).
Caton et al. (1993) estudaram o efeito da adição de extratos de fungos sobre as características digestivas de uma gramínea de clima temperado e também não relataram diferença na concentração de $\mathrm{N}-\mathrm{NH}_{3}$, que apresentou valor médio de 19,15 mg/100 mL. Lewis etal.(1996), em experimento com novilhos consumindo uma dieta com $70 \%$ de volumoso, também não notaram alterações nos parâmetros ruminais ( $\mathrm{pH}$ e N-NH${ }_{3}$ ) com a suplementação enzimática (celulase e xilanase).

$\mathrm{Na}$ Figura 2 constam os valores de $\mathrm{pH}$ ruminal em função dos tempos de coleta.

A adição das enzimas às dietas contendo silagem e feno não alterou $(\mathrm{P}>0,05)$ o pH ruminal. Yang et al. (1999) também não observaram efeito da suplementação enzimática em dietas com $45 \%$ de feno de alfafa sobre o $\mathrm{pH}$ ruminal, obtendo valores de 5,$85 ; 5,88$ e 5,83, respectivamente, para os níveis de 0,11 e 23 g. Da mesma forma, Hristov et al. (2000) estudaram o efeito da forma de aplicação das enzimas fibrolíticas (diluída e adicionada à dieta total ou introduzida no rúmen) em dietas contendo $35 \%$ de silagem de milho e não encontraram diferença no $\mathrm{pH}$ ruminal, que apresentou valor médio de 6,28.

Observou-se menor $\mathrm{pH}$ ruminal para as dietas contendo silagem de milho em comparação àquelas contendo feno, no tempo 4 horas após a alimentação, provavelmente em razão dos processos fermentativos ocorridos no silo, ocorrendo maior concentração de ácidos, que, após a ingestão, contribuíram para a redução do $\mathrm{pH}$ ruminal. De acordo com Silva \& Queiroz (2002), a forragem ensilada sofre fermentação como consequência da atividade microbiana, a qual

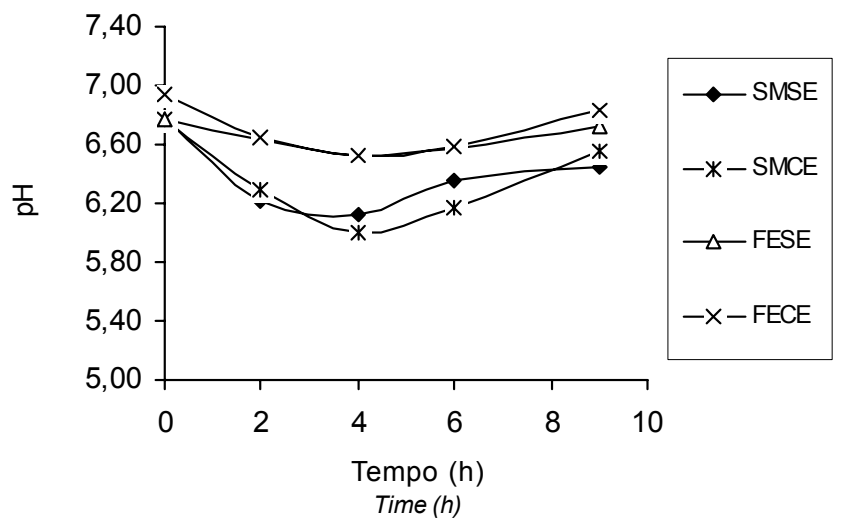

Figura 2 - pH ruminal em função dos tempos de amostragem, para as dietas SMSE (silagem de milho sem enzimas fibrolíticas), SMCE (silagem de milho com enzimas fibrolíticas), FESE (feno de tifton 85 sem enzimas fibrolíticas) e FECE (feno de tifton 85 com enzimas fibrolíticas).

Figure 2 - Ruminal pH in the ruminal fluid of bovines fed CS (corn silage with no fibrolytic enzymes), CSFE (corn silage with fibrolytic enzymes), TH (Tifton 85 hay with no fibrolytic enzymes) and THFE (Tifton 85 hay with fibrolytic enzymes). 
produz, entre outros, os ácidos lático e acético. Segundo os autores, o ácido lático (principal ácido presente nas silagens) e os íons provenientes de outros ácidos, contribuem para diminuir o $\mathrm{pH}$ da silagem.

Da mesma forma, Van Soest (1994) afirma que a preservação da forragem ensilada por meio da fermentação depende da produção de ácido lático para estabilizar a silagem a um $\mathrm{pH}$ baixo. $\mathrm{O} \mathrm{pH}$, por sua vez, depende do suprimento adequado de açúcares (proveniente dos grãos de amido, no caso da silagem de milho) para proporcionar a fermentação ácida e superar a capacidade tampão da forragem.

$\mathrm{O}$ valor médio do $\mathrm{pH}$ verificado neste estudo foi superior a 6,0 . Portanto, favoreceu a manutenção do meio ruminal adequado para a aderência das bactérias celulolíticas às partículas. De acordo com Hoover (1986), o potencial de digestão da fibra poderia ser prejudicado pelas variações de pH, de modo que valores abaixo de 5,5 limitariam a atuação dos microrganismos celulolíticos sobre a fibra.

Tenkanen et al. (1995) verificaram que o $\mathrm{pH}$ pode afetar a atividade das celulases e xilanases extraídas dos fungos Trichoderma reesei e Aspergillus oryzae sobre a celulose e xilana, comprometendo as interações eletrostáticas e a força iônica. Os autores observaram que o aumento da força iônica provocou redução na adsorção da xilanase com o substrato e que valores de $\mathrm{pH}$ abaixo de 4,9 dificultaram a ligação entre enzima e substrato.
Segundo McAllister et al.(2001), as enzimas celulolíticas produzidas por microrganismos ruminais atuam, em grande parte, com eficiência em pH acima de 6,2. Entretanto, o pH ótimo para atuação das enzimas fibrolíticas extraídas de fungos aeróbicos pode variar de 4,0 a valores superiores a 6,0 . Portanto, o pH não foi fator limitante para a atuação das enzimas fibrolíticas exógenas e microbianas, possibilitando a ocorrência do efeito sinergístico entre ambas durante a degradação da fibra no rúmen, conforme mencionado por Wallace et al. (2001).

As estimativas referentes ao volume ruminal, à taxa de diluição, ao tempo de retenção, à taxa de reciclagem da fase líquida e à taxa de fluxo encontram-se na Tabela 2.

Não houve efeito da interação $(\mathrm{P}>0,05)$ fontes de volumoso $\times$ níveis de enzima, porém, constatou-se efeito da fonte de volumoso $(\mathrm{P}<0,05)$ sobre a taxa de diluição (TD), o tempo de retenção (TR), a taxa de reciclagem (TRec) e a taxa de fluxo do fluido ruminal (TF). Os animais que consumiram feno apresentaram maior TD e, conseqüentemente, menor TR $(\mathrm{P}<0,05)$ que aqueles alimentados com as dietas contendo silagem, provavelmente em razão do aumento na produção de saliva, causado pelo maior teor de fibra do feno. Da mesma forma, a TRec e a TF foram maiores $(\mathrm{P}<0,05)$ para as dietas contendo feno.

O volume de líquido ruminal médio obtido para estas dietas foi de 29,35 L, inferior ao observado por Berchielli et

Tabela 2 - Volume de líquido de rúmen (VLR), taxa de diluição (TD), tempo de retenção no rúmen-retículo (TR), taxa de reciclagem (TRec) e taxa de fluxo do fluido ruminal (TF), de acordo com as dietas experimentais

Table 2 - Means of rumen fluid volume (RFV), dilution rate (DR), rumen-reticulum retention time (RRT), turnover rate (TR) and flow rate of ruminal fluid (FRRF) on the experimental diets

\begin{tabular}{|c|c|c|c|c|c|c|c|c|}
\hline \multirow{4}{*}{$\begin{array}{l}\text { Volumoso } \\
\text { Forage } \\
\text { Enzima }\end{array}$} & \multicolumn{4}{|c|}{$\begin{array}{c}\text { Efeito principal } \\
\text { Main effect }\end{array}$} & \multicolumn{4}{|c|}{$\begin{array}{l}\text { Média } \\
\text { Mean }\end{array}$} \\
\hline & \multirow{2}{*}{\multicolumn{2}{|c|}{$\begin{array}{l}\text { SM } \\
C S\end{array}$}} & \multirow{2}{*}{\multicolumn{2}{|c|}{$\begin{array}{l}\mathrm{FE} \\
T H\end{array}$}} & \multirow{2}{*}{\multicolumn{2}{|c|}{$\begin{array}{l}\text { Volumoso } \\
\text { Forage }\end{array}$}} & \multirow{2}{*}{\multicolumn{2}{|c|}{$\begin{array}{l}\text { Enzima } \\
\text { Enzyme }\end{array}$}} \\
\hline & & & & & & & & \\
\hline & SE & $\mathrm{CE}$ & SE & $\mathrm{CE}$ & SM & FE & SE & $\mathrm{CE}$ \\
\hline Enzyme & $-E$ & $+E$ & $-E$ & $+E$ & $-C S$ & $T H$ & $-E$ & $+E$ \\
\hline
\end{tabular}

Parâmetro

Parameter

\begin{tabular}{|c|c|c|c|c|c|c|c|c|}
\hline VLR (L) & 29,67 & 29,03 & 29,23 & 29,47 & $29,35 \mathrm{~A}$ & $29,35 \mathrm{~A}$ & $29,45 \mathrm{a}$ & $29,25 \mathrm{a}$ \\
\hline \multicolumn{9}{|l|}{$R F V(L)$} \\
\hline $\operatorname{TD}(\% / h)$ & 9,29 & 10,56 & 11,15 & 13,12 & $9,84 \mathrm{~B}$ & $12,07 \mathrm{~A}$ & $10,07 b$ & $11,84 \mathrm{a}$ \\
\hline \multicolumn{9}{|l|}{$D R \quad(\% / h)$} \\
\hline TR (h) & 10,96 & 9,71 & 9,02 & 7,80 & $10,35 \mathrm{~A}$ & $8,34 \mathrm{~B}$ & $10,01 \mathrm{a}$ & $8,69 \mathrm{a}$ \\
\hline \multicolumn{9}{|l|}{$R R T(h)$} \\
\hline TRec（vezes/dia） & 2,22 & 2,49 & 2,73 & 3,02 & $2,31 \mathrm{~B}$ & $2,87 \mathrm{~A}$ & $2,47 \mathrm{a}$ & $2,71 \mathrm{a}$ \\
\hline \multicolumn{9}{|l|}{$T R$ (times /day) } \\
\hline $\mathrm{TF}(\mathrm{L} / \mathrm{h})$ & 2,73 & 3,00 & 3,31 & 3,71 & $2,79 \mathrm{~B}$ & $3,47 \mathrm{~A}$ & $2,99 a$ & $3,31 \mathrm{a}$ \\
\hline$F R R F(L / h)$ & & & & & & & & \\
\hline
\end{tabular}

$\mathrm{SM}=$ silagem de milho; FE = feno de tifton; SE = sem adição de enzimas; $\mathrm{CE}=$ com adição de enzimas. Médias seguidas de letras diferentes na mesma linha, maiúscula para as fontes de volumoso (silagem de milho e feno de tifton) e minúscula para os níveis de enzima $(0$ e $12 \mathrm{~g} / a n i m a l / d i a)$, diferem ( $<<0,05)$ pelo teste Tukey.

$C S=$ corn silage; $T H=$ tifton hay; $-E=$ without enzyme; $+E=$ with enzyme. Means followed by different letters in a row, capital letters for each forage (corn silage and Tifton hay) and small letters for each enzymatic level ( 0 and $12 \mathrm{~g} /$ animal/day) differ $(P<0.05)$ by Tukey test. 
al. (1996), de 37,98 L, em animais consumindo dieta com relação volumoso:concentrado de 80:20. Quando expresso em porcentagem do peso vivo (\% PV), o VLR médio verificado neste estudo correspondeu a $8,50 \%$ do PV, abaixo da variação média de 15 a $21 \%$ do PV, descrita por Owens \& Goetsch (1988) para o volume ruminal de bovinos. Segundo esses autores, as variações no volume de líquido ruminal podem ser atribuídas aos níveis de concentrado das dietas e à qualidade da forragem utilizada.

O valor médio estimado para a taxa de diluição $(11,03 \% / \mathrm{h})$ foi próximo ao de 11,7\%/h, relatado por Gunter et al. (1990), e superior ao de 6,97\%/h, obtido por Bürger et al. (2000), para uma dieta com relação volumoso:concentrado de 70:30, em que o volumoso foi constituído de feno de coastcross. O valor médio da taxa de reciclagem foi de 2,62 vezes/dia, próximo ao relatado por Berchielli et al. (1996), de 2 vezes/dia.

As dietas contendo silagem de milho apresentaram valor médio da taxa de diluição de $9,84 \% / \mathrm{h}$, inferior ao estimado para as dietas contendo feno de tifton $(12,07 \% / \mathrm{h})$. Ospina (1995), citado por Bürger et al. (2000), mencionou que, em geral, animais alimentados com volumosos apresentam maiores taxas de passagem da fase líquida que aqueles alimentados com concentrado, provavelmente em virtude da maior produção de saliva. Embora a proporção volumoso:concentrado tenha sido a mesma, as dietas contendo feno apresentaram maior teor de FDN, o que corrobora essa informação.

Não houve efeito $(\mathrm{P}>0,05)$ da adição de enzimas fibrolíticas sobre TR, TRec e TF. Beauchemin et al. (1999), em experimento com vacas em lactação consumindo cevada, não observaram efeito da adição de enzimas (celulase e xilanase) sobre a TD, entretanto, notaram redução no TR das partículas. Feng et al. (1996) também verificaram menor TR com a adição de enzimas exógenas ao feno de gramínea.

A adição de enzimas aumentou $(\mathrm{P}<0,05)$ a TD das dietas avaliadas. Hristov et al. (1998), avaliando o efeito da forma de fornecimento de um complexo enzimático (celulase, xilanase e amilase), não observaram efeito da adição das enzimas sobre a taxa de diluição, que apresentou valor médio de 11,11\%/h. De acordo com Owens \& Goetsch (1988), o nível de ingestão é um dos fatores que poderiam causar variações na taxa de diluição. Caton et al. (1993), em experimento com novilhos em pastejo, também não registraram efeito da suplementação com extratos de Aspergillus oryzae sobre a taxa de diluição ruminal.

Tabela 3 - Estimativas da taxa de passagem de partículas da silagem de milho e do feno de tifton 85 (sem e com a adição de enzimas) no rúmen-retículo $\left(k_{1}\right)$ e no pós-rúmen $\left(k_{2}\right)$ e dos tempos de trânsito (TT) e retenção no rúmen-retículo (TRR) e no pós-rúmen (TRPR) e do tempo médio de retenção total (TMRT)

Table 3 - Means of the particle passage rate of corn silage and Tifton 85 hay with and without enzymes addition, at rumen-reticulum $\left(k_{1}\right)$ and at the postrumen $\left(k_{2}\right)$, transit time $(T T)$, retention time at the rumen-reticulum $(R T R)$, retention time at the post rumen (RTPR) and mean total retention time (MTRT)

\begin{tabular}{|c|c|c|c|c|c|c|c|c|}
\hline \multirow{3}{*}{$\begin{array}{l}\text { Volumoso } \\
\text { Forage } \\
\text { Enzima }\end{array}$} & \multicolumn{4}{|c|}{$\begin{array}{c}\text { Efeito principal } \\
\text { Main effect }\end{array}$} & \multicolumn{4}{|c|}{$\begin{array}{c}\text { Média } \\
\text { Mean }\end{array}$} \\
\hline & \multicolumn{2}{|c|}{$\begin{array}{c}\mathrm{SM} \\
\mathrm{CS}\end{array}$} & \multicolumn{2}{|c|}{$\begin{array}{l}\mathrm{FE} \\
T H\end{array}$} & \multicolumn{2}{|c|}{$\begin{array}{l}\text { Volumoso } \\
\text { Forage }\end{array}$} & \multicolumn{2}{|c|}{$\begin{array}{l}\text { Enzima } \\
\text { Enzyme }\end{array}$} \\
\hline & SE & $\mathrm{CE}$ & $\mathrm{SE}$ & $\mathrm{CE}$ & SM & $\mathrm{FE}$ & $\mathrm{SE}$ & $\mathrm{CE}$ \\
\hline Enzyme & $-E$ & $+E$ & $-E$ & $+E$ & $-C S$ & $T H$ & $-E$ & $+E$ \\
\hline \multicolumn{9}{|l|}{$\begin{array}{l}\text { Parâmetro } \\
\text { Parameter }\end{array}$} \\
\hline $\begin{array}{l}\mathrm{k}_{1}(\% / \mathrm{h}) \\
k_{1}(\% / h)\end{array}$ & 3,51 & 3,29 & 2,95 & 3,08 & $3,40 \mathrm{~A}$ & $3,02 \mathrm{~A}$ & $3,23 \mathrm{a}$ & $3,19 \mathrm{a}$ \\
\hline $\begin{array}{l}\mathrm{k}_{2}(\% / \mathrm{h}) \\
k_{2}(\% / h)\end{array}$ & 19,90 & 20,54 & 19,14 & 18,18 & $20,22 \mathrm{~A}$ & $18,66 \mathrm{~A}$ & $19,52 \mathrm{a}$ & $19,36 \mathrm{a}$ \\
\hline $\begin{array}{l}\text { TT (h) } \\
\text { TT (h) }\end{array}$ & 9,11 & 11,41 & 9,97 & 9,08 & $10,26 \mathrm{~A}$ & $9,52 \mathrm{~A}$ & $9,54 \mathrm{a}$ & $10,25 \mathrm{a}$ \\
\hline $\begin{array}{l}\text { TRR (h) } \\
R T R(h)\end{array}$ & 30,16 & 33,13 & 35,26 & 31,67 & $31,64 \mathrm{~A}$ & $33,46 \mathrm{~A}$ & $32,71 \mathrm{a}$ & $32,40 \mathrm{a}$ \\
\hline $\begin{array}{l}\text { TRPR (h) } \\
R T P R(h)\end{array}$ & 5,16 & 4,81 & 5,35 & 5,66 & $4,98 \mathrm{~A}$ & $5,45 \mathrm{~A}$ & $5,25 \mathrm{a}$ & $5,19 \mathrm{a}$ \\
\hline $\begin{array}{l}\operatorname{TMRT}(\mathrm{h}) \\
\operatorname{MTRT}(h)\end{array}$ & 35,32 & 37,61 & 38,56 & 43,06 & $36,46 \mathrm{~A}$ & $40,81 \mathrm{~A}$ & $36,94 \mathrm{a}$ & $40,34 \mathrm{a}$ \\
\hline
\end{tabular}

$\mathrm{SM}=$ silagem de milho; FE = feno de tifton; SE = sem adição de enzimas; $C E$ = com adição de enzimas. Médias seguidas de letras diferentes na mesma linha, maiúscula para as fontes de volumoso (silagem de milho e feno de tifton) e minúscula para os níveis de enzima $(0$ e $12 \mathrm{~g} / a n i m a l / d i a)$, diferem $(P<0,05)$ pelo teste Tukey.

$C S=$ corn silage; $T H=$ tifton hay; $-E=$ without enzyme; $+E=$ with enzyme. Means followed by different letters in a row, capital letters for each roughage (corn silage and tifton hay) and small letters for each enzymatic level ( 0 and $12 \mathrm{~g} /$ animal/day) differ $(P<0.05)$ by the Tukey test. 
As estimativas da taxa de passagem de partículas no rúmen-retículo $\left(\mathrm{k}_{1}\right)$ e no pós-rúmen $\left(\mathrm{k}_{2}\right)$, do tempo de retenção (TR), do tempo de trânsito (TT) e do tempo médio de retenção total (TMRT) constam na Tabela 3. Não houve interação $(\mathrm{P}>0,05)$ entre as fontes de volumoso e os níveis de enzimas para as variáveis analisadas.

A taxa de passagem do alimento no rúmen é uma variável de grande importância, pois determina o fluxo da digesta pelo trato digestivo. No caso de forrageiras tropicais, esses valores são baixos, principalmente, em razão do alto teor de fibra (Soares, 2002), como observado neste estudo.

As fontes de volumoso não alteraram a taxa de passagem das partículas, o TT, oTR e o TMRT, assim como a adição de enzimas à silagem de milho e ao feno de tifton não influenciou $(\mathrm{P}>0,05)$ os parâmetros avaliados.

$\mathrm{O}$ valor médio observado para a taxa de passagem no rúmen $\left(\mathrm{k}_{1}\right)$ para ambos os volumosos foi de $3,20 \% / \mathrm{h}$, inferior ao de 4,96\%/h encontrado por Bürger et al. (2000), em bezerros alimentados com feno de coastcross e diferentes níveis de concentrado. Por outro lado, a taxa de passagem pós-rúmen $\left(\mathrm{k}_{2}\right)$ obtida neste estudo foi superior $(19,46 \% / \mathrm{h})$ à encontrada por esses autores $(7,30 \% / \mathrm{h})$.

Korndörfer (1999), avaliando a cinética digestiva em ovinos alimentados com feno de Brachiaria decumbens em duas idades de corte ( 28 e 56 dias), encontrou valores médios para $\mathrm{k}_{1} \mathrm{ek}_{2} \mathrm{de} 4,41 \% / \mathrm{h}$ e $8,71 \% / \mathrm{h}$, respectivamente, porém, utilizaram o modelo de Dhanoa e colaboradores para os cálculos da taxa de passagem. De acordo com Owens \& Hanson (1992), a não-adequação do ajuste dos parâmetros matemáticos aos componentes fisiológicos pode prejudicar o conhecimento da fisiologia de passagem da dieta pelo trato gastrintestinal, a segregação de subcomponentes da digesta e o comportamento do marcador.

Beauchemin et al. (1999) não verificaram efeito da adição de enzimas fibrolíticas sobre a taxa de passagem de partículas no rúmen $(3,54 \% / \mathrm{h})$ ao utilizarem relação volumoso: concentrado de 45:55. Yang et al. (1999), analisando o efeito da suplementação enzimática em vacas em lactação consumindo $45 \%$ de feno de alfafa, não constataram efeito do suplemento sobre o tempo de retenção ruminal, que apresentou média de 32,45 horas. Segundo Mertens \& Ely (1982), as cinéticas de trânsito e de passagem estariam relacionadas, principalmente, ao nível de consumo, à forma física da dieta, às diferenças na ruminação entre animais, ao tipo de marcador utilizado na determinação da curva de excreção fecal, à relação volumoso:concentrado e aos fatores climáticos.

O tempo de trânsito (TT) e o tempo médio de retenção total (TMRT) obtidos para o feno de tifton $(9,52$ e 40,81 horas, respectivamente) foram inferiores aos valores de 13,08 e 62,34 h, respectivamente, reportados por Bürger et al. (2000), em estudo com dietas contendo feno de coastcross.

O tempo de retenção no rúmen-retículo encontrado neste trabalho para o feno de tifton foi de 33,5 horas, inferior ao obtido por Soares (2002), de 55 horas, em animais consumindo capim-elefante.

\section{Conclusões}

A suplementação com enzimas fibrolíticas em dietas com silagem de milho ou feno de tifton como volumoso não afetou o $\mathrm{pH}$ ruminal, as concentrações de $\mathrm{N}-\mathrm{NH}_{3}$ e a cinética de líquidos e sólidos em bovinos, mas aumentou a taxa de diluição.

\section{Literatura Citada}

AGRICULTURAL AND FOOD RESEARCH COUNCIL - AFRC. Technical committee on responses to nutrients: energy and protein requirements of ruminants. Wallingford: $C A B$ International, $1995.159 \mathrm{p}$.

BEAUCHEMIN, K.A.; RODE, L.M.; SEWALT, J.H. Fibrolytic enzymes increase fiber digestibility and growth rate of steers fed dry forages. Canadian Journal of Animal Science, v.75, p.641-644, 1995 .

BEAUCHEMIN, K.A.; YANG, W.Z.; RODE, L.M. Effects of grain source and enzyme additive on site and extent of nutrient digestion on dairy cows. Journal of Dairy Science, v.82, p.378-390, 1999.

BERCHIELli, T.T.; RODRIGUEZ, N.M.; GONÇALVES, L.C. Polietilenoglicol e cobalto-EDTA como marcadores da fase líquida ruminal. Arquivos Brasileiros de Medicina Veterinária e Zootecnia, v.48, p.463-471, 1996.

BÜRGER, P.J.; PEREIRA, J.C.; QUEIROZ, A.C. et al. Taxas de passagem e cinética da degradação ruminal em bezerros holandeses alimentados com dietas contendo diferentes níveis de concentrado. Revista Brasileira de Zootecnia, v.29, p.225-235, 2000.

CATON, J.S.; ERICKSON, D.O.; CAREY, D.A. et al. Influence of Aspergillus oryzae fermentation extract on forage intake, site of digestion, in situ degradability and duodenal amino acid flow in steers grazing cool-season pasture. Journal of Animal Science, v.71, p.779-787, 1993.

CHESSON, A. Feed enzymes. Animal Feed Science and Technology, v.45, p.65-79, 1993.

COLUCCI, P.E. Comparative digestion and digesta kinetics in sheep and cattle. Guelph: University of Guelph, 1984. 221 p. Thesis (Ph.D. Thesis Animal Science) - University of Guelph, 1984.

COLUCCI, P.E.; MACLEOD, G.K.; GROVUM, W.L. et al. Digesta kinetics in sheep and cattle fed diets with different forage to concentrate ratios at high and low intakes. Journal of Dairy Science, v.73, p.2143-2156, 1990.

FENG, P.; HUNT, C.W.; PRITCHARD, G.T. et al. Effect of enzyme preparations on in situ and in vitro degradation and in vivo digestive characteristics of mature cool-season grass forage in beef steers. Journal of Animal Science, v.74, p.1349-1357, 1996.

FENNER, H. Method for determining total volatile bases in rumen fluid by steam distillation. Journal of Dairy Science, v.48, n.2, p.249-251, 1965. 
GROVUM, W.L.; WILLIAMS, V.J. Rate of passage of digesta in sheep. 4. Passage of marker through the alimentary tract and the biological relevance of rate-constants derived from the changes in concentration of marker in faeces. British Journal of Nutrition, v.30, p.313-329, 1973.

GUNTER, S.A.; KRYSL, L.J.; JUDKINS, M.B. et al. Influence of branched-chain fatty acid supplementation on voluntary intake, site of digestion, ruminal fermentation, digesta kinetics and microbial sinthesys in beef heifers consuming grass hay. Journal of Animal Science, v.68, p.2885-2892, 1990.

HOOVER, W.H. Chemical factors involved in ruminal fiber digestion. Journal of Dairy Science, v.69, p.2755-2766, 1986.

HRISTOV, A.N.; McALLISTER, T.A.; CHENG, K.-J. Intraruminal supplementation with increasing levels of exogenous polisacharide-degrading enzymes: effects on nutrient digestion in cattle feed barley grain diets. Journal of Animal Science, v.78, p.477-487, 2000 .

KORNDÖRFER, C.M. Eficiência de utilização do feno de Brachiaria decumbens na alimentação de ovinos Santa Inês. Piracicaba: Escola Superior Luiz de Queiroz, 1999. 110p. Tese (Doutorado em Energia Nuclear na Agricultura), - Escola Superior Luiz de Queiroz, 1999.

LEWIS, G.E.; HUNT, C.W.; SANCHEZ, W.K. et al. Effect of directfed fibrolytic enzymes on the digestive characteristics of a forage-based diet fed to beef steers. Journal of Animal Science, v.74, p.3020-3028, 1996.

MAENG, W.J.; BALDWIN, R.L. Dynamics of fermentation of purified diet and microbial growth in the rumen. Journal of Dairy Science, v.54, p.636-642, 1976.

McALLISTER, T.A.; HRISTOV, A.N.; BEAUCHEMIN, K.A. et al. Enzymes in ruminant diets. In: BEDFORD, M.R., PARTRIDGE, G.G. (Eds.). Enzymes in farm nutrition. Oxon: Cab International, 2001. p.273-298.

MERTENS, D.R.; ELY, L.O. Relationship of rate and extent of digestion to forage utilization - a dynamic model evaluation. Journal of Animal Science, v. 54, p.895-905, 1982.

NATIONAL RESEARCH COUNCIL - NRC. Nutrient requeriments of beef cattle. 7.ed. Washington, D.C.: National Academy Press, 2001. 381p.

NEWBOLD, J. Proposed mechanisms for enzymes as modifiers of ruminal fermentation. In: FLORIDA RUMINANT NUTRITION SYMPOSIUM, 16., 1997, Gainesville. Proceedings... Gainesville: 1997. p.3-17.

OWENS, F.N.; GOETSCH, A.L. Ruminal fermentation. In: CHURCH, D.C. (Ed.). The ruminant animal digestive physiology and metabolism. New Jersey: Prentice Hall, 1988. p.145-171.

OWENS, F.N.; HANSON, C.F. External and internal markers for appraising site and extent of digestion in ruminants. Journal of Dairy Science, v.75, p.2605-2617, 1992.

STATISTICAL ANALYSES SYSTEM - SAS. Users' guide: statistics. 5.ed. Cary: 1985. v.1, 956p.

SATTER, L.D.; SLYTER, L.L. Effect of ammonia concentration on the rumen and microbial protein production in vitro. British Journal Nutrition, v.32, p.199-208, 1974.
SCHINGOethe, D.J.; STEGEMAN, G.A.; TREACHER, R.J. Response of lactanting dairy cows to a cellulase and xylanase enzyme mixture applied to forage at the time of feeding. Journal of Dairy Science, v.82, p.996-1003, 1999.

SILVA, D.J.; QUEIROZ, A.C. Análises de alimentos: métodos químicos e biológicos. 3 ed. Viçosa, MG: Universidade Federal de Viçosa, 2002. 235p.

SOARES, J.P. Fatores limitantes do consumo de capim-elefante cv. Napier utilizando vacas leiteiras confinadas. Jaboticabal: Universidade Estadual Paulista, 2002. 110p. Tese (Doutorado em Zootecnia) - Universidade Estadual Paulista, 2003.

TENKANEN, M.; THORNTON, J.; VIIKARI, L. An acetylglucomannan esterase of Aspergillus oryzae: purification, characterization and role in the hydrolysis of O-acetyl-galactoglucomannan. Journal Biotechnology, v.42, p.197-206, 1995.

UDÉN, P.; COLUCCI, P.E.; Van SOEST, P.J. Investigation of chromium, cerium and cobalt as markers in digesta rate of passage studies. Journal Science and Food Agriculture, v.31, p.625-632, 1980 .

VALADARES, R.F.D. Níveis de proteína em dieta de bovinos: consumo, digestibilidade, eficiência de síntese microbiana, amônia ruminal, uréia plasmática e excreções de uréia e creatinina. Belo Horizonte: Universidade Federal de Minas Gerais, 1997. 101p. Tese (Doutorado em Ciência Animal) - Universidade Federal de Minas Gerais, 1997.

Van SOEST, P.J. Nutritional ecology of the ruminant. 2.ed. Ithaca: Comstock Publication Association, 1994. 476p.

VARGA, G.A.; KOLVER, E.S. Microbial and ruminal limitations to fiber digestion and utilization. Journal Nutrition, v.127, p.819-823, 1997.

VIEIRA, P.F. Efeito do formaldeído na proteção de proteínas e lipídeos em rações para ruminantes. Viçosa, MG: Universidade Federal de Viçosa, 1980. 98p. Tese (Doutorado em Zootecnia) - Universidade Federal de Viçosa, 1980.

WALLACE, R.J.; WALLACE, S.J.A.; McKAIN, N. Influence of supplementary fibrolytic enzymes on the fermentation of corn and grass silages by mixed ruminal microorganims in vitro. Journal of Animal Science, v.79, p.1905-1916, 2001.

YANG, W.Z.; BEAUCHEMIN, K.A.; RODE, L.M. Effects of an enzyme feed additive on extent of digestion and milk production of lactating dairy cows. Journal of Dairy Science, v.82, p.391-403, 1999 . 